\title{
INFLUÊNCIA DO EMPREGO DE VAZÕES VARIÁVEIS DE ÁGUA DE ENXÁGUE SOBRE A CINÉTICA DE REMOÇÃO DE RESÍDUOS DE SOLUÇÃO DETERGENTE ALCALINA EM TROCADOR DE CALOR FEIXE TUBULAR
}

\author{
B. P. BICALHO ${ }^{1}$, L. KUNIGK ${ }^{2}$ e R. GEDRAITE ${ }^{1}$ \\ ${ }^{1}$ Universidade Federal de Uberlândia, Faculdade de Engenharia Química \\ 2 Centro Universitário do IMT, Depto de Engenharia Química e de Alimentos \\ E-mail para contato: barbarapbicalho@gmail.com
}

\begin{abstract}
RESUMO - Este artigo apresenta uma contribuição acerca da investigação sobre o emprego de vazões variáveis de água de enxágue na cinética de remoção de resíduos de solução detergente alcalina em trocador de calor feixe tubular. $\mathrm{O}$ estudo foi baseado na técnica de limpeza tradicionalmente empregada em sistemas de limpeza CIP da indústria. O emprego de valores de vazão variáveis se mostrou mais eficaz na remoção dos resíduos, apresentando maior taxa de variação inicial no comportamento temporal da relação entre as concentrações instantânea e final. Adicionalmente, foi constatada a economia do volume total de água utilizado no processo para o emprego de valores menores de vazão.
\end{abstract}

\section{INTRODUÇÃO}

A técnica de limpeza Clean-in-Place (CIP) é amplamente utilizada na indústria de alimentos e na indústria farmacêutica, dentre outras, visando evitar a parada de produção e a desmontagem parcial ou total dos equipamentos de processamento. Sabe-se que diversas pesquisas têm sido realizadas nos últimos anos para procurar formas de melhorar o procedimento (Bansal e Chen, 2006; Bremer et al., 2006). Tanto a tensão de cisalhamento aplicada quanto as reações químicas entre o fluido em escoamento e os depósitos formados são importantes na remoção de incrustações. A indústria de laticínios sofre de problemas específicos associados com a limpeza de equipamentos de processo, incluindo trocadores de calor (Georgiadis et al., 1998). Presentemente, o procedimento de limpeza envolve a lavagem do maquinário com solução detergente diluída, a fim de remover adequadamente os resíduos e incrustações que tendem a favorecer a contaminação. Depois de terminada a limpeza, o equipamento de processo deve ser enxaguado criteriosamente para remover todos os vestígios dos agentes de limpeza.

Este trabalho apresenta uma contribuição ao tema, estudando o comportamento temporal da cinética de remoção de resíduos de solução de detergente alcalino em trocador de calor feixe tubular, estimulada por pulsos na vazão, durante a etapa de enxágue posterior à etapa de limpeza alcalina.

\section{MATERIAIS E MÉTODOS}


Na Figura 1 é apresentada a planta-piloto utilizada neste trabalho, a qual foi operada em regime descontínuo, e formada basicamente pelos seguintes elementos: (i)- tanque principal em aço inox com capacidade de aproximadamente $250 \mathrm{~L}$, (ii)- trocador de calor do tipo casco e tubos em aço inox, (iii)- bomba de deslocamento positivo para movimentação do produto alimentício, (iv)- bomba centrífuga para a movimentação do agente de aquecimento, reservatório cilíndrico vertical para armazenamento da água de aquecimento (Salvagnini e Gedraite, 2001).

O sistema eletrônico de aquisição de dados e controle do processo é apresentado pelo fluxograma da Figura 2. A plataforma responsável pela aquisição de dados e controle da planta em estudo é composta por um SECD (Sistema Eletrônico de Coleta de Dados), funcionando como um computador de processo e compreendendo basicamente as interfaces e um sistema computacional que, além do controle, proporcionam a aquisição e armazenamento dos dados de interesse (Lobato et al, 2014).

Figura 1 - Planta piloto utilizada

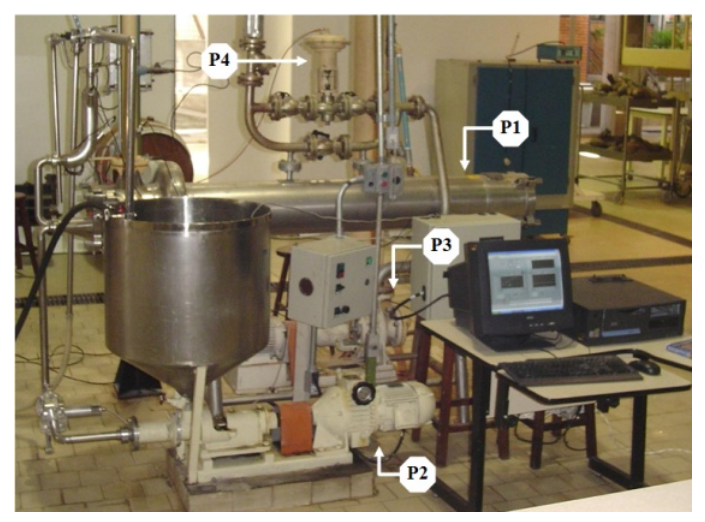

Figura 2 - Fluxograma de instrumentação do sistema

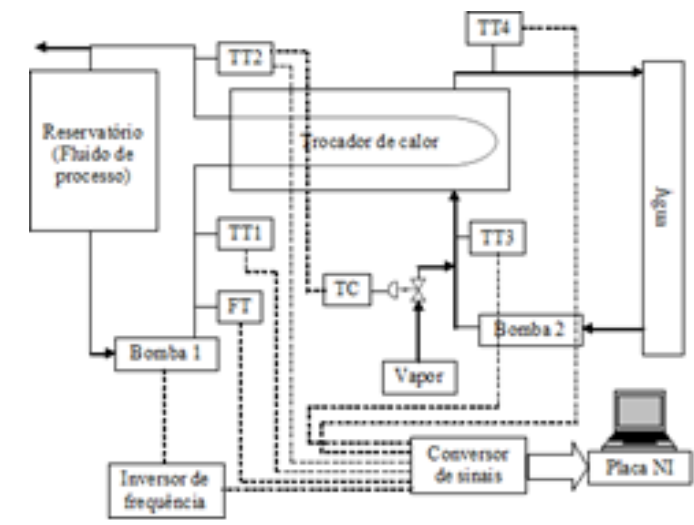

Foi seguido o procedimento experimental utilizado no desenvolvimento deste trabalho (Chen et al., 2004) . A solução de detergente alcalino foi colocada em circulação nos tubos internos do trocador de calor, com temperatura e vazão controladas respectivamente em $50^{\circ} \mathrm{C}$ e 9,0 L/min, durante uma hora, retornando a solução ao tanque de hidróxido de sódio quente. Monitorou-se os valores dinâmicos do $\mathrm{pH}$, vazão e temperaturas da solução e do agente de aquecimento. Uma vez concluída a etapa de limpeza com a solução detergente, é iniciado o processo de enxágue com água potável para remoção do detergente residual aderido às paredes dos tubos do feixe tubular e que foi utilizado na etapa anterior. O equipamento é colocado em regime estacionário de operação, alimentando-se o bocal de entrada do trocador com água pré-aquecida em torno de $50^{\circ} \mathrm{C}$, mantendo-se controladas a temperatura em $50^{\circ} \mathrm{C} \mathrm{e}$ a vazão em 9,0 L·min.-1, direcionando a saída do fluído de processo à um tanque intermediário de pequenas dimensões utilizado para a medição do $\mathrm{pH}$ sem turbulência.

O procedimento experimental citado nos parágrafos anteriores foi repetido para valores distintos de vazão de água de enxágue $(9,0 \mathrm{~L} / \mathrm{min}, 10,5 \mathrm{~L} / \mathrm{min}$ e $12,0 \mathrm{~L} / \mathrm{min})$. As grandezas dinâmicas do sistema registradas ao longo dos ensaios foram: temperaturas, vazão e pH. A identificação não-paramétrica foi baseada nas curvas de resposta do processo quando excitados por sinais de entrada do tipo degrau, impulso ou senoidal. A partir dessas curvas, 
foram extraídos modelos aproximados, de baixa ordem, utilizados para descrever o comportamento dinâmico do processo (Aguirre, 2007). Neste trabalho, estes modelos foram utilizados para representar o comportamento dinâmico do $\mathrm{pH}$ em função do tempo, tendo-se optado por ajustar um modelo de $1^{\text {a }}$ ordem com atraso de transporte. Estes empregam parâmetros típicos de funções de transferência, a saber: ganho $(K p)$, atraso de transferência $(\tau p)$ e atraso de transporte ou tempo morto $(\theta p)$. Foi utilizado o Método de Sundaresan e Krishnaswamy (Campos e Teixeira, 2007) para a determinação dos parâmetros do modelo, por apresentar melhores resultados no ajuste dos dados experimentais (Gedraite et al., 2010).

O modelo da planta em estudo foi desenvolvido de maneira a estudar o consumo de água na etapa descrita, contemplando o cenário de variações do tipo degrau no valor da vazão de água de enxágue. Neste contexto, o modelo levou em conta o valor do $\mathrm{pH}$ considerado como set point obtido pela simulação da mesma planta, porém sem variação no valor da vazão de água de enxágue no tempo correspondente a $\theta p+4 \cdot \tau p$ (Gormezano, 2007; Garcia, 2005). Na Figura 3 é apresentado o diagrama de simulação típico, considerando o modelo de referencia identificado e o modelo do processo. Os valores dos parâmetros $K p$, $\tau p$ e $\theta p$ foram obtidos por interpolação, para cada vazão estudada, a partir dos dados experimentais obtidos.

Figura 3- Diagrama de simulação do processo estudado

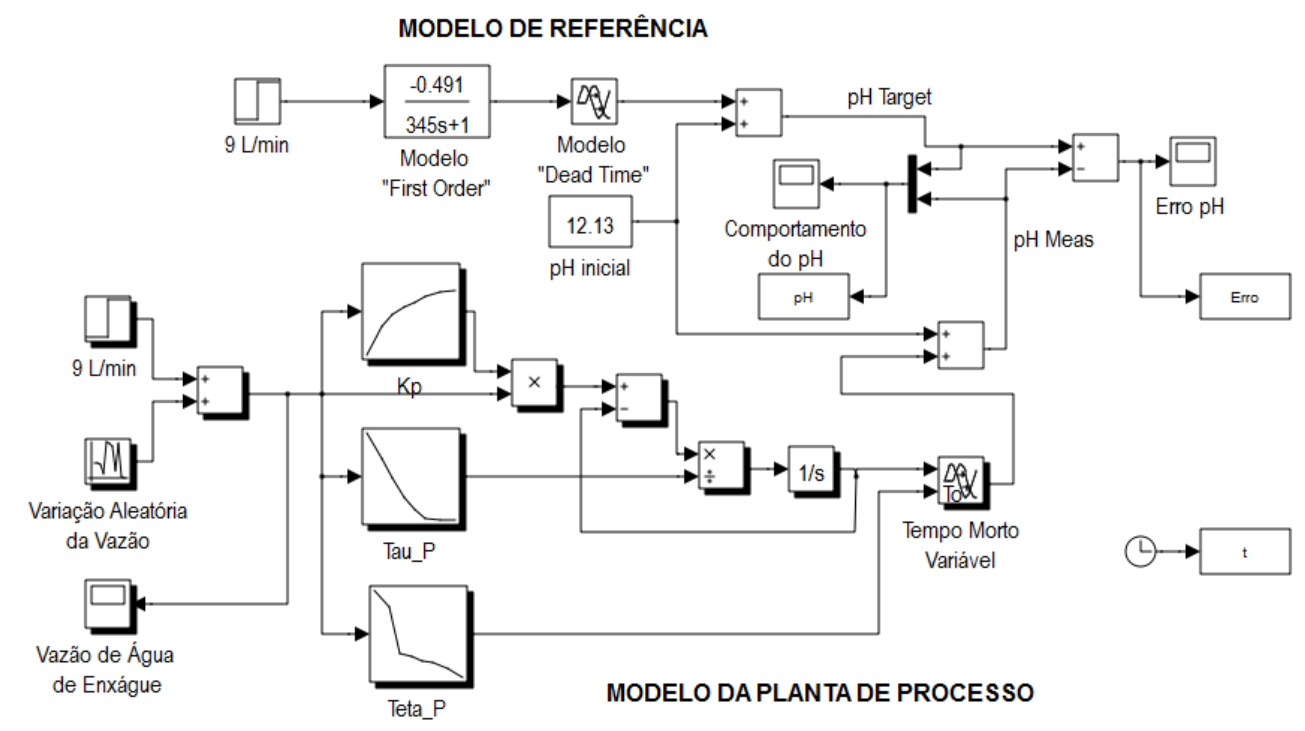

Para cada uma das vazões previamente estudadas por Melero Jr. (2011) foram avaliadas três novas situações, nas quais foram realizados degraus de $1 \mathrm{~L} / \mathrm{min}, 2 \mathrm{~L} / \mathrm{min}$ e $3 \mathrm{~L} / \mathrm{min}$ no instante $\theta p+0,3 \cdot \tau p$, até que estas atingissem o $\mathrm{pH}$ de referência (Ogata, 2000). A partir deste ponto, foram analisados os volumes de água de enxágue obtidos nas novas simulações em comparação com os obtidos sem que houvesse nenhuma variação nos valores de vazão.

\section{RESULTADOS E DISCUSSÃO}

Neste contexto, foi possível verificar que as simulações realizadas para baixos valores de vazão, entre $4 \mathrm{~L} / \mathrm{min}$ e $7,5 \mathrm{~L} / \mathrm{min}$, foram aquelas com maior economia no consumo de água 
quando comparado ao consumo previamente obtido na simulação de referência, até 69 L. No entanto, esta economia não foi suficiente para que o consumo fosse inferior ao consumo ótimo, obtido na simulação de referência na vazão de $10,5 \mathrm{~L} / \mathrm{min}, 216 \mathrm{~L}$. Dentre todos os ensaios realizados, o único resultado abaixo do avaliado como ótimo ocorreu com $14 \mathrm{~L} / \mathrm{min}$ ao se aplicar o degrau de amplitude igual a $3 \mathrm{~L} / \mathrm{min}$, quando o consumo foi reduzido a $209 \mathrm{~L}$. A Tabela 1 apresenta o resumo dos testes feitos e resultados obtidos.

Tabela 1. Resultados obtidos com os testes realizados

\begin{tabular}{|c|c|c|c|c|c|c|c|c|c|c|}
\hline $\begin{array}{c}\text { Vazão } \\
{\left[\text { [L-min }{ }^{-1}\right]}\end{array}$ & $\begin{array}{l}\text { Parâr } \\
\delta K_{p}\end{array}$ & $\begin{array}{l}\text { os do modelo } \\
\text { H/L-min.-1] } \\
\theta_{p}-[\mathrm{s}]\end{array}$ & $\begin{array}{c}\text { Tempo processo } \\
\text { vazão constante } \\
\left(\theta_{p}+4 \mathrm{x} \tau_{\mathrm{p}}\right) \\
{[\mathrm{s}]}\end{array}$ & \begin{tabular}{|c|} 
pH final \\
processo vazão \\
constante \\
(simulação) \\
[Adim.]
\end{tabular} & $\begin{array}{c}\text { Volume final } \\
\text { processo vazão } \\
\text { constante } \\
\text { (simulação) } \\
\text { [L] }\end{array}$ & $\begin{array}{c}\text { Tempo } \\
\text { degrau } \\
\left(\theta_{p}+0.3 \times \tau_{p}\right) \\
{[s]}\end{array}$ & $\begin{array}{l}\text { Degraus } \\
\text { aplicados } \\
\text { [L-min }:^{-1} \text { ] }\end{array}$ & $\begin{array}{c}\text { Tempo processo } \\
\text { com degrau } \\
\text { (simulação) } \\
{[\mathrm{s}]}\end{array}$ & $\begin{array}{c}\text { Volume final } \\
\text { processo com } \\
\text { degrau } \\
\text { (simulação) } \\
{[\mathrm{L}]}\end{array}$ & $\begin{array}{c}\text { Economia do volume } \\
\text { de água entre processo } \\
\text { vazão constante e com } \\
\text { degrau } \\
{[\mathrm{L}]}\end{array}$ \\
\hline \multirow{3}{*}{4} & $K_{p}$ & $-1,083$ & \multirow{3}{*}{3974} & \multirow{3}{*}{7,839} & \multirow{3}{*}{263,9} & \multirow{3}{*}{1415,45} & 1 & 3139,3 & 237 & 26,9 \\
\hline & $\tau_{p}$ & 691,5 & & & & & 2 & 3416,35 & 293 & $-29,1$ \\
\hline & $\theta_{p}$ & 1208 & & & & & 3 & 2778,59 & 251,7 & 12,2 \\
\hline \multirow{3}{*}{6} & $K_{p}$ & $-0,722$ & \multirow{3}{*}{3137,5} & \multirow{3}{*}{7,879} & \multirow{3}{*}{312,3} & \multirow{3}{*}{1098,8} & 1 & 2394,72 & 267,8 & 44,5 \\
\hline & $\tau_{p}$ & 551 & & & & & 2 & 2178,63 & 251,9 & 60,4 \\
\hline & $\theta_{p}$ & 933,5 & & & & & 3 & 2003,09 & 243,3 & 69 \\
\hline \multirow{3}{*}{7,5} & $K_{p}$ & $-0,578$ & \multirow{3}{*}{2225} & \multirow{3}{*}{7,797} & \multirow{3}{*}{276,3} & \multirow{3}{*}{589,6} & 1 & 1777,93 & 239,9 & 36,4 \\
\hline & $\tau_{p}$ & 442 & & & & & 2 & 1603,73 & 231,9 & 44,4 \\
\hline & $\theta_{p}$ & 457 & & & & & 3 & 1520,17 & 234 & 42,3 \\
\hline \multirow{3}{*}{2} & $K_{p}$ & $-0,491$ & \multirow{3}{*}{1765,5} & \multirow{3}{*}{7,799} & \multirow{3}{*}{261,2} & \multirow{3}{*}{524,15} & 1 & 1566,71 & 249,9 & 11,3 \\
\hline & $\tau_{p}$ & 335,5 & & & & & 2 & 1572,83 & 268,2 & -7 \\
\hline & $\theta_{p}$ & 423,5 & & & & & 3 & 1346,11 & 311,5 & $-50,3$ \\
\hline \multirow{3}{*}{10,5} & $K_{p}$ & $-0,421$ & \multirow{3}{*}{1459} & \multirow{3}{*}{7,913} & \multirow{3}{*}{216,6} & \multirow{3}{*}{460} & 1 & 1331,63 & 211,8 & 4,8 \\
\hline & $\tau_{p}$ & 270 & & & & & 2 & 1287,68 & 218 & $-1,4$ \\
\hline & $\theta_{p}$ & 379 & & & & & 3 & 1353,95 & 244,8 & $-28,2$ \\
\hline \multirow{3}{*}{12} & $K_{p}$ & $-0,358$ & \multirow{3}{*}{1218,5} & \multirow{3}{*}{7,92} & \multirow{3}{*}{240,7} & \multirow{3}{*}{424,85} & 1 & 1162,99 & 241,7 & -1 \\
\hline & $\tau_{p}$ & 214,5 & & & & & 2 & 1253,96 & 275 & $-34,3$ \\
\hline & $\theta_{p}$ & 360,5 & & & & & 3 & 1028,39 & 232,2 & 8,5 \\
\hline \multirow{3}{*}{14} & $K_{p}$ & $-0,304$ & & & & & 1 & 963,77 & 231,4 & 28,8 \\
\hline & $\tau_{p}$ & 210,5 & 1130,3 & 7,967 & 260,2 & 351,45 & 2 & 874,621 & 217,6 & 42,6 \\
\hline & $\theta_{p}$ & 288,3 & & & & & 3 & 814,413 & 209 & 51,2 \\
\hline & $K_{p}$ & $-0,274$ & & & & & 1 & 948,567 & 260,1 & 11,4 \\
\hline 16 & $\tau_{p}$ & 208 & 1033,2 & 7,801 & 271,5 & 263,6 & 2 & 921,986 & 263,3 & 8,2 \\
\hline & $\theta_{p}$ & 201,2 & & & & & 3 & 986,337 & 294,5 & -23 \\
\hline
\end{tabular}

\section{CONCLUSÕES}

Os resultados obtidos apontam para significativa redução no tempo de processo de limpeza CIP com o emprego dos degraus nos valor da vazão de água de enxágue, além da redução no volume de água de lavagem utilizado para a significativa maioria dos casos.

Com exceção do valor de vazão igual a $14 \mathrm{~L} / \mathrm{min}$, os menores valores de vazão de água de enxágue apresentaram resultados que sugerem maior economia no volume de água gasta. Em particular, para o valor de $6 \mathrm{~L} / \mathrm{min}$, a redução no volume de água gasto foi a mais significativa.

Os modelos matemáticos empregados são bastante simples e adequados para fácil implementação na base de dados de um sistema digital de controle tipicamente utilizado na indústria alimentícia, visando realizar o acompanhamento em tempo real da operação da etapa de enxágue do processo de limpeza pelo sistema CIP.

Deve ser ressaltado que, como os modelos empregados neste trabalho são semiempíricos, toda sistemática adotada é válida para inferência das mesmas grandezas nas outras etapas envolvidas em processos de limpeza pelo sistema CIP. 


\section{AGRADECIMENTOS}

Os autores agradecem à UFU, ao IMT e à Fapemig (Fundação de Amparo à Pesquisa do Estado de Minas Gerais) pelo apoio em pesquisas no projeto No TEC-APQ-02100-12 (Estudo da Otimização de Sistema de Limpeza CIP).

\section{NOMENCLATURA}

FT: Transmissor de vazão.

P1: Trocador de calor feixe tubular.

P2: Bomba de deslocamento positivo.

P3: Bomba centrífuga.

P4: Válvula de controle pneumática.

TC: Controlador de temperatura.

TT1: Transmissor de temperatura 1.

TT2: Transmissor de temperatura 2.

TT3: Transmissor de temperatura 3.

TT4: Transmissor de temperatura 4.

\section{REFERÊNCIAS}

AGUIRRE, L. A. Introdução à identificação de sistemas: técnicas lineares e não lineares aplicadas a sistemas reais. Ed. UFMG. 2007.

BANSAL, B., CHEN, X. D. A Critical Review of Milk Fouling in Heat Exchangers. Comprehensive Reviews in Food Science and Food Safety. Institute of Food Technologists. v.5, p. $27-33,2006$.

BREMER, P.J., FILLERY, S. \& McQUILLAN, A. J. Laboratory scale Clean-In-Place (CIP) studies on the effectiveness of different caustic and acid wash steps on the removal of dairy biofilms. Int. J. Food Microbiol., v.106 , p. 254 - 262, 2006.

CAMPOS, M. C. M. M; TEIXEIRA, H. C. G. Controles Típicos de Equipamentos e Processos Industriais. São Paulo, SP: Ed. Edgard Blucher. 1 ed., 2007. 
CHEN, X. D., ÖZKAN, N., QIN, F., XIN, H. \& LIN, L. An Effective CIP Procedure for Removing Dairy Protein Based Deposit - A Laboratory Investigation. ECI Conference on Heat Exchanger Fouling and Cleaning: Fundamentals and Applications. New Mexico, USA, 2003

GARCIA, C. Modelagem e Simulação de Processos Industriais e de Sistemas Dinâmicos. EDUSP, São Paulo, 2005.

GEDRAITE, R.; KUNIGK, L.; RIBEIRO, S.; MELERO Jr., V.; VASCONCELOS, F.; SISLIAN, R. (2010). Experimental investigation about the milk protein based deposit removal kinetics. In: Proc. of World congress on communication and arts, WCCA, Guimarães - Portugal.

GEORGIADIS, M. C., ROTSTEIN, G. E. \& MACCHIETTO, S. Modeling and Simulation of Shell and Tube Heat Exhangers under Milk Fouling. AIChe Journal. v. 44, No. 4, p. 959 - 971, 1998.

GORMEZANO, L. Desenvolvimento e implementação de sistema para avaliar a cinética de remoção de resíduos presentes nos tubos de trocador de calor feixe tubular. Dissertação (Mestrado). São Caetano do Sul. Centro Universitário do Instituto Mauá de Tecnologia, 2007.

LOBATO, F. S., MALAGONI, R. A., GEDRAITE, R. Estudo da cinética de remoção de resíduos na etapa de enxágue de sistema de limpeza CIP. In: Anais XI Simpósio de Mecânica Computacional II Encontro Mineiro de Modelagem Computacional SIMMEC/EMMCOMP 2014. Universidade Federal de Juiz de Fora (UFJF), Juiz de Fora/MG, Brasil. 28-30 mai. 2014. Associação Brasileira de Engenharia Mecânica e Industrial - ABEMEC.

MELERO Jr., V. 2011. 'Instrumentação e identificação de um processo de sanitização cinética CIP'. Centro Universitário do Instituto Mauá de Tecnologia, São Caetano do Sul - (Dissertação de Mestrado).

OGATA, K. Engenharia de Controle Moderno. Rio de Janeiro: Prentice Hall do Brasil, $3^{a}$ edição, 2000

SALVAGNINI, W.; GEDRAITE, R. (2001). Rotina de Experimento para trocador de calor feixe tubular. São Caetano do Sul, SP: CEUN-IMT. 